\title{
Hypomania after augmenting venlafaxine and olanzapine with sarcosine in a patient with schizophrenia: a case study
}

This article was published in the following Dove Press journal:

Neuropsychiatric Disease and Treatment

27 February 2015

Number of times this article has been viewed

\section{Dominik Strzelecki \\ Justyna Szyburska \\ Magdalena Kotlicka-Antczak \\ Olga Kałużyńska}

Department of Affective and Psychotic Disorders, Medical University of Łódź, Central Clinical Hospital, Łódź, Poland
Correspondence: Dominik Strzelecki Department of Affective and Psychotic Disorders, Medical University of Łódź, Central Clinical Hospital, ul Czechosłowacka 8/10, 92-216 Łódź, Poland

Tel +4842 6757236

Fax +48 426757403

Email dominik.strzelecki@umed.lodz.pl
Abstract: Glutamate is the main excitatory neurotransmitter in the central nervous system. Dysfunction of the glutamatergic system plays an important and well-established role in the pathogenesis of schizophrenia. Agents with glutamatergic properties such as $N$-methylD-aspartate receptor coagonists (ie, glycine, D-cycloserine) and glycine transporter type 1 inhibitors (eg, sarcosine, bitopertin) are investigated in schizophrenia with special focus on negative and cognitive symptomatology. In this article, we describe a case of a 34-year-old woman with diagnosis of schizophrenia with persistent moderate negative and cognitive symptoms, a participant of the Polish Sarcosine Study (PULSAR) treated with olanzapine (25 mg per day) and venlafaxine ( $75 \mathrm{mg}$ per day). During ten weeks of sarcosine administration ( $2 \mathrm{~g}$ per day) the patient's activity and mood improved, but in the following 2 weeks, the patient reported decreased need for sleep, elevated mood, libido and general activity. We diagnosed drug-induced hypomania and recommended decreasing the daily dose of venlafaxine to $37.5 \mathrm{mg}$ per day, which resulted in normalization of mood and activity in about 1 week. After this change, activity and mood remained stable and better than before adding sarcosine, and subsequent depressive symptoms were not noted. We describe here the second case report where sarcosine induced important affect changes when added to antidepressive and antipsychotic treatment, which supports the hypothesis of clinically important glutamate-serotonin interaction.

Keywords: MNDA receptor, glutamatergic system, serotoninergic system

\section{Introduction}

Glutamate is the main excitatory neurotransmitter of the brain. Dysfunctional glutamatergic transmission leads to important neuropsychiatric consequences playing a primary role in the pathogenesis of numerous disorders, such as schizophrenia, addictions, or Alzheimer's dementia. ${ }^{1-5}$ Currently investigated possibilities of pharmacological intervention in schizophrenia are focused on enhancing the $N$-methyl-Daspartate (NMDA) receptor activity according to the hypo-NMDA receptor hypothesis of that psychosis. NMDA receptor is one of the glutamatergic ionotropic receptors of crucial importance for cognition (eg, attention and memory dependent on long-term potentiation process) which is probably also related to negative symptoms present in schizophrenia. ${ }^{6-8}$ In literature, there are two pharmacological opportunities described for enhancing function of the NMDA receptor. The direct method relies on administration of glycine (natural coagonist of the NMDA receptor) or other coagonists (D-cycloserine and D-serine), and the indirect method relies on inhibiting the glycine transporter type I (GlyT-1) with sarcosine, bitopertin (RG1678), or ALX-5407.9-12 Sarcosine (N-methylglycine) has been used in several small studies and the results seem to be promising in ameliorating cognitive and negative symptoms where efficacy of 
using known antipsychotics is rather limited. ${ }^{13,14}$ Previously published studies also indicate positive changes in affective symptomatology during the use of NMDA coagonists or sarcosine, ${ }^{15-20}$ but interestingly, NMDA receptor antagonists such as ketamine and memantine also have antidepressive effects. $^{21-23}$

Addition of sarcosine - a natural, widespread amino acid - is currently considered as a beneficial and safe augmentation method of neuroleptic treatment in schizophrenia. In the available literature, significant improvement in both negative symptoms subscale and total symptomatology scores in the Positive and Negative Syndrome Scale after sarcosine use was described. ${ }^{14,15}$ In these projects, patients received a dose of $2 \mathrm{~g}$ of sarcosine per day.

We present a case of a woman with diagnosis of schizophrenia in a stable mental condition treated with olanzapine and venlafaxine (started due to negative and affective symptoms) who started taking $2 \mathrm{~g}$ of sarcosine or placebo per day as a participant of the Polish Sarcosine Study (PULSAR; NLM identifier: NCT01503359), ${ }^{24}$ a 6-month randomized double-blind placebo controlled trial. After an initial improvement in the first 10 weeks, the patient developed hypomanic symptoms in the next 2 weeks and it was necessary to decrease the dose of venlafaxine or sarcosine/placebo. Initially, information on whether the patient was in a study or a control group was concealed. Therefore, we decided to decrease the dose of antidepressant. We reduced the dose of venlafaxine by half, and after 7-10 days we observed mood stabilization without secondary depressive episode. The patient continued participation in the trial. Standard unblinding procedure revealed that the patient had been taking sarcosine throughout the course of the study. This case with recently published observations indicates the need for revision of the recommended dosage of sarcosine or concomitant drugs in patients with schizophrenia, as well as the need to take the risk of serotonin-glutamate interaction into consideration. In a previously reported case, we decreased the dose of sarcosine; here we decided to reduce the dose of antidepressant with similarly good effect. ${ }^{25}$

\section{Case report}

The patient was a 34-year-old female, suffering from schizophrenia for 14 years (diagnosed according to the 10th revision of International Statistical Classification of Diseases and Related Health Problems criteria) who had previously been psychiatrically hospitalized four times, with the last time being 5 years ago. The first episode and three following exacerbations were typical paranoid syndromes with delusions, auditory hallucinations, and disorganization. In a stable period, the patient presented moderate severity of negative symptoms (blunted and inappropriate affect, social withdrawal, decreased overall activity) and anxiety, and moderate cognitive problems (attention and memory difficulties), which were the main indication for participation in the study. In positive symptomatology, the patient described only transient mild delusions of reference. Improvement in affective symptoms was achieved earlier by the use of venlafaxine and for this reason the drug was continued. No manic or hypomanic episodes in the patient were noted in the past.

After receiving information about sarcosine, the patient signed an informed consent form and started receiving the augmentation. Laboratory tests were performed (complete blood count, electrolytes, liver and renal parameters, lipids, prolactin and thyroid-stimulating hormone levels) which showed no deviations from the reference values. The patient had no neurological, endocrine, or other chronic comorbidities at the time of our treatment. On enrollment visit, we excluded changes in the treatment in the last 3 months, ongoing alcohol, and drug dependence or use in last 6 months. The patient was currently unemployed and on disability living allowance. Before adding sarcosine, olanzapine (25 mg per day) and venlafaxine ( $75 \mathrm{~g}$ per day) had been prescribed for several months without any significant mental state changes. Olanzapine was started over 3 years ago and venlafaxine a year ago due to depressive and negative symptoms.

During the first 10 weeks of sarcosine administration at $2 \mathrm{~g}$ per day, the patient reported a gradual improvement of overall activity, concentration, and mood. After the next 2 weeks, the patient reported moderately increased mood, drive, and libido, excessive activity with talkativity, and decreased need for sleep (to 2-4 hours). The patient found these symptoms "strange" and asked for the modification of the treatment. She described the overall impact of sarcosine as positive, and therefore it was decided to maintain the sarcosine supplementation, but the dose of venlafaxine was been reduced by half to $37.5 \mathrm{mg}$ per day. The patient declared adherence to the medication regimen.

After this change, the intensity of excitation and mood elation decreased in about 1 week (for details, see Table 1) without secondary depressive episode. There were no external circumstances to explain hypomanic symptoms.

\section{Discussion}

Glutamatergic agents have recently been a focus of great interest to neuropharmacologists and clinicians. ${ }^{26,27}$ The efficacy of sarcosine and other GlyT-1 inhibitors, such as RG1678 in 
Table I Psychiatric assessment scores

\begin{tabular}{lllll}
\hline & $\begin{array}{l}\text { Before sarcosine } \\
\text { Week } \mathbf{0}\end{array}$ & $\begin{array}{l}\text { Sarcosine 2 g plus } \\
\text { venlafaxine } \mathbf{7 5} \mathbf{~ m g} \\
\text { Week 4 }\end{array}$ & $\begin{array}{l}\text { Sarcosine 2 g plus } \\
\text { venlafaxine 75 mg } \\
\text { Week 12 (hypomania) }\end{array}$ & $\begin{array}{l}\text { Sarcosine 2 g plus } \\
\text { venlafaxine 37.5 mg } \\
\text { Week 16 }\end{array}$ \\
\hline PANSS_P & 13 & 10 & 10 & 9 \\
PANSS_N & 25 & 20 & 14 & 16 \\
PANSS_G & 29 & 28 & 25 & 20 \\
PANSS_T & 67 & 58 & 49 & 45 \\
Calgary & 0 & 0 & 0 & 0 \\
HAMA & 8 & 9 & 9 & 3 \\
YMRS & 0 & 0 & 15 & 0 \\
\hline
\end{tabular}

Notes: The first visit was before the start of sarcosine. The second visit was after 4 weeks of taking the $2 \mathrm{~g}$ dose of amino acid. On the third visit after a further 8 weeks, due to hypomania, the daily dose of venlafaxine was reduced to $37.5 \mathrm{mg}$. After a further 4 weeks, the patient was taking $2 \mathrm{~g}$ of sarcosine and $37.5 \mathrm{mg}$ venlafaxine daily. The dose of olanzapine was $25 \mathrm{mg}$ per day during the study.

Abbreviations: PANSS, Positive and Negative Syndrome Scale for Schizophrenia; P, positive symptoms; N, negative symptoms; G, general psychopathology; T, total score; Calgary, Calgary Depression Scale for Schizophrenia; HAMA, Hamilton Anxiety Rating Scale for Schizophrenia; YMRS, Young Mania Rating Scale.

the treatment of schizophrenia, has been under investigation in recent years. ${ }^{28,29} \mathrm{It}$ is considered that these compounds may have beneficial effects on the negative, affective, and cognitive symptomatology in schizophrenia. In the described patient, the hypomanic state occurred, which had not been previously noted and described in any patient taking sarcosine. Besides the direct excitatory effect of sarcosine, possible reasons for these symptoms may be related to the amino acid-induced potentiation of serotonergic transmission that was previously increased with venlafaxine, a selective serotonin and noradrenaline reuptake inhibitor (but at $75 \mathrm{mg}$ per day acting as a selective serotonin reuptake inhibitor only) and olanzapine (which also has serotoninergic potential). We hypothesize that sarcosine may increase serotonergic and dopaminergic transmission in prefrontal lobes and also in the hippocampus, which are areas of key importance for negative, cognitive, and affective symptomatology and where NMDA receptor is present in high density. Hypomania presented here could be a result of the synergistic effect of sarcosine, venlafaxine, and olanzapine on serotonergic transmission. There is no data about interaction of sarcosine with other drugs (with the exception of our previous case) or drug metabolism changes. ${ }^{25}$

Symptoms of induced hypomania appeared later than those associated typically with the beginning of antidepressive treatment, but occurrence of hypomania or mania during antidepressive treatment is possible at different times. Because a hypomanic state was not present with stable venlafaxine and olanzapine doses, we assume that adding the sarcosine was of crucial importance. Mechanisms of the glutamatergic impact on serotoninergic functions are actually not clear; we cannot clearly explain the 10-week delay of discomfort appearance after sarcosine starting, and this period is longer than the delay of selective serotonin reuptake inhibitors' and other antidepressants' effect (usually 2-4 weeks). Based on both this report and previous observations, we perceive that proper simultaneous use of substances with glutamatergic and serotoninergic properties may generate a synergistic effect, which can also be used in refractory cases..$^{25,30}$

The described clinical problem indicates the necessity of determining the range of sarcosine or antidepressant doses used in concomitant treatment of schizophrenia. We suggest considering a flexible use of antidepressant dose, particularly when complicated by hypomania or irritability (also when these were present in the past). In our previous case study, we successfully proposed to adjust sarcosine daily dosing to between 1 and $2 \mathrm{~g}$ per day, particularly in combination with serotonergic substances. ${ }^{25}$ The symptoms hypothetically induced by sarcosine described in our earlier article had some features of hypomania but did not meet all of its criteria. Summarizing the results of the two works, we come to the conclusion that the normalization of mood can be achieved by adjusting the dose of sarcosine as well as antidepressants.

Due to the methodological limitations of single case reports, conclusions should be formulated carefully. The patient described in this article was included in the PULSAR study - a 6-month randomized double-blind placebo controlled trial - which evaluated the efficacy and safety of sarcosine in patients with schizophrenia. The PULSAR study has been reviewed by the Ethics Committee of Medical University of Łódź and was therefore performed in accordance with the ethical standards laid down in the 1975 Declaration of Helsinki.

\section{Acknowledgment}

The study is supported by Polish Ministry of Science and Higher Education [Grant number N N402 268836].

\section{Disclosure}

The authors report no conflicts of interest in this work. 


\section{References}

1. Coyle JT. The glutamatergic dysfunction hypothesis for schizophrenia. Harv Rev Psychiatry. 1996;3:241-253.

2. Carlsson A, Waters N, Waters S, Carlsson ML. Network interactions in schizophrenia - therapeutic implications. Brain Res Brain Res Rev. 2000;31:342-349.

3. Olney JW, Newcomer JW, Farber NB. NMDA receptor hypofunction model of schizophrenia. J Psychiatr Res. 1999;33:523-533.

4. Gass JT, Olive MF. Glutamatergic substrates of drug addiction and alcoholism. Biochem Pharmacol. 2008;75:218-265.

5. Hu NW, Ondrejcak T, Rowan MJ. Glutamate receptors in preclinical research on Alzheimer's disease: update on recent advances. Pharmacol Biochem Behav. 2012;100:855-862.

6. Tang TT, Yang F, Chen BS, et al. Dysbindin regulates hippocampal LTP by controlling NMDA receptor surface expression. Proc Natl Acad Sci U S A. 2009;106:21395-21400.

7. Manahan-Vaughan D, Wildförster V, Thomsen C. Rescue of hippocampal LTP and learning deficits in a rat model of psychosis by inhibition of glycine transporter-1 (GlyT1). Eur J Neurosci. 2008;28:1342-1350.

8. Gruber O, Chadha Santuccione A, Aach H. Magnetic resonance imaging in studying schizophrenia, negative symptoms, and the glutamate system. Front Psychiatry. 2014;5:32.

9. Kantrowitz J, Javitt DC. Glutamatergic transmission in schizophrenia: from basic research to clinical practice. Curr Opin Psychiatry. 2012; 25:96-102.

10. de Bartolomeis A, Sarappa C, Magara S, Iasevoli F. Targeting glutamate system for novel antipsychotic approaches: relevance for residual psychotic symptoms and treatment resistant schizophrenia. Eur $J$ Pharmacol. 2012;682:1-11.

11. López-Muñoz F, Álamo C. Neurobiological background for the development of new drugs in schizophrenia. Clin Neuropharmacol. 2011; 34:111-126.

12. Tuominen HJ, Tiihonen J, Wahlbeck K. Glutamatergic drugs for schizophrenia. Cochrane Database Syst Rev. 2006;19:CD003730.

13. Hashimoto K, Malchow B, Falkai P, Schmitt A. Glutamate modulators as potential therapeutic drugs in schizophrenia and affective disorders. Eur Arch Psychiatry Clin Neurosci. 2013;263:367-377.

14. Singh SP, Singh V. Meta-analysis of the efficacy of adjunctive NMDA receptor modulators in chronic schizophrenia. CNS Drugs. 2011; 25:859-885.

15. Tsai GE, Lin PY. Strategies to enhance N-methyl-D-aspartate receptormediated neurotransmission in schizophrenia, a critical review and meta-analysis. Curr Pharm Des. 2010;16:522-537.

16. Heresco-Levy U, Ermilov M, Shimoni J, Shapira B, Silipo G, Javitt DC. Placebo-controlled trial of D-cycloserine added to conventional neuroleptics, olanzapine, or risperidone in schizophrenia. Am J Psychiatry. 2002; $159: 480-482$.

17. Heresco-Levy U, Javitt DC, Ermilov M, Silipo G, Shimoni J. Doubleblind, placebo-controlled, crossover trial of D-cycloserine adjuvant therapy for treatment-resistant schizophrenia. Int J Neuropsychopharmacol. 1998;1:131-135.
18. Heresco-Levy U, Javitt DC, Ermilov M, Mordel C, Horowitz A, Kelly D. Double-blind, placebo-controlled, crossover trial of glycine adjuvant therapy for treatment-resistant schizophrenia. Br J Psychiatry. 1996; 169:610-617.

19. Strzelecki D, Kropiwnicki P, Rabe-Jabłońska J. [Augmentation of antipsychotics with glycine may ameliorate depressive and extrapyramidal symptoms in schizophrenic patients - a preliminary 10-week open-label study]. Psychiatr Pol. 2013;47:609-620. Polish.

20. Huang CC, Wei IH, Huang CL, et al. Inhibition of glycine transporter-I as a novel mechanism for the treatment of depression. Biol Psychiatry. 2013;74:734-41.

21. Diazgranados N, Ibrahim L, Brutsche NE, et al. A randomized add-on trial of an N-methyl-D-aspartate antagonist in treatment-resistant bipolar depression. Arch Gen Psychiatry. 2010;67:793-802.

22. Ferguson JM, Shingleton RN. An open-label, flexible-dose study of memantine in major depressive disorder. Clin Neuropharmacol. 2007; 30:136-144.

23. Muhonen LH, Lönnqvist J, Juva K, Alho H. Double-blind, randomized comparison of memantine and escitalopram for the treatment of major depressive disorder comorbid with alcohol dependence. J Clin Psychiatry. 2008;69:392-399.

24. Medical University of Lodz. Effect of sarcosine on symptomatology, quality of life, oxidative stress and glutamatergic parameters in schizophrenia (PULSAR). Available from: http://clinicaltrials.gov/ show/NCT01503359. NLM identifier: NCT01503359. Accessed October 11, 2014

25. Strzelecki D, Szyburska J, Rabe-Jabłońska J. Two grams of sarcosine in schizophrenia - is it too much? A potential role of glutamate-serotonin interaction. Neuropsychiatr Dis Treat. 2014;10:263-266.

26. Singh SP, Singh V, Kar N, Chan K. Efficacy of antidepressants in treating the negative symptoms of chronic schizophrenia: meta-analysis. Br J Psychiatry. 2010;197:174-179.

27. Javitt DC. Glycine transport inhibitors in the treatment of schizophrenia. Handb Exp Pharmacol. 2012;213:367-399.

28. Alberati D, Moreau JL, Lengyel J, et al. Glycine reuptake inhibitor RG1678: a pharmacologic characterization of an investigational agent for the treatment of schizophrenia. Neuropharmacology. 2012;62: $1152-1161$

29. Umbricht D, Alberati D, Martin-Facklam M, et al. Effect of bitopertin, a glycine reuptake inhibitor, on negative symptoms of schizophrenia: a randomized, double-blind, proof-of-concept study. JAMA Psychiatry. 2014;71:637-46.

30. de Bartolomeis A, Buonaguro EF, Iasevoli F. Serotonin-glutamate and serotonin-dopamine reciprocal interactions as putative molecular targets for novel antipsychotic treatments: from receptor heterodimers to postsynaptic scaffolding and effector proteins. Psychopharmacology (Berl). 2013;225:1-19.
Neuropsychiatric Disease and Treatment

\section{Publish your work in this journal}

Neuropsychiatric Disease and Treatment is an international, peerreviewed journal of clinical therapeutics and pharmacology focusing on concise rapid reporting of clinical or pre-clinical studies on a range of neuropsychiatric and neurological disorders. This journal is indexed on PubMed Central, the 'PsycINFO' database and CAS,

\section{Dovepress}

and is the official journal of The International Neuropsychiatric Association (INA). The manuscript management system is completely online and includes a very quick and fair peer-review system, which is all easy to use. Visit http://www.dovepress.com/testimonials.php to read real quotes from published authors. 